\title{
Perinatal cortical infarction within middle cerebral artery trunks
}

\author{
Paul Govaert, Erika Matthys, Alexandra Zecic, Filip Roelens, Ann Oostra,
} Bart Vanzieleghem

\begin{abstract}
Aim-To define neonatal pial middle cerebral artery infarction.

Methods-A retrospective study was made of neonates in whom focal arterial infarction had been detected ultrasonographically. A detailed study was made of cortical middle cerebral artery infarction subtypes.
\end{abstract}

Results-Forty infarctions, with the exception of those in a posterior cerebral artery, were detected ultrasonographically over a period of 10 years. Most were confirmed by computed tomography or magnetic resonance imaging. Factor V Leiden heterozygosity was documented in three. The onset was probably antepartum in three, and associated with fetal distress before labour in one. There were 19 cases of cortical middle cerebral artery stroke. The truncal type $(n=13)$ was more common than complete $(n=5)$ middle cerebral artery infarction. Of six infarcts in the anterior trunk, four were in term infants and five affected the right hemisphere. Clinical seizures were part of the anterior truncal presentation in three. One of these infants, with involvement of the primary motor area, developed a severe motor hemisyndrome. The Bayley Mental Developmental Index was above 80 in all of three infants tested with anterior truncal infarction. Of seven patients with posterior truncal infarction, six were at or near term. Six of these lesions were left sided. Clinical seizures were observed in three. A mild motor hemisyndrome developed in at least three of these infants due to involvement of parieto-temporal nonprimary cortex.

Conclusions-Inability to differentiate between truncal and complete middle cerebral artery stroke is one of the explanations for the reported different outcomes. Severe motor hemisyndrome can be predicted from neonatal ultrasonography on the basis of primary motor cortex involvement. Clinical seizures were recognised in less than half of the patients with truncal infarction; left sided presentation was present in the posterior, but not the anterior truncal type of infarction. Asphyxia is a rare cause of focal arterial infarction. (Arch Dis Child Fetal Neonatal Ed 2000;82:F59-F63)

Keywords: cortical infarction; middle cerebral artery; severe motor hemisyndrome.
Focal arterial infarction is an important cause of permanent brain injury in the perinatal period. Estimates from brain imaging suggest an incidence of 0.2 per 1000 neonates. Precise definition of the vessel involved is often impossible, partly because of the difficulty of angiographic confirmation and limited correlations with post mortem findings.

The left middle cerebral artery tends to be affected predominantly. ${ }^{23}$ For infarction in the entire field of the middle cerebral artery the previously optimistic prognosis ${ }^{4-7}$ has been replaced with guarded realism. ${ }^{8}$ For partial cortical (pial) and lacunar infarction, the outcome is virtually unknown. ${ }^{9-11}$ Prognostic variability can be explained by unpredictable brain plasticity, ${ }^{12}$ and the variable accuracy with which lesions are anatomically defined. An additional reason may be overdiagnosis of infarction based on white matter attenuation with computed tomography or focal hyperechogenicity within ischaemic but not necessarily necrotic tissue.

We report the retrospective analysis of 13 cases of infarction in one of the two major cortical trunks of the middle cerebral artery.

\section{Methods}

We retrospectively studied the ultrasound brain scans of infants born between 1988 and 1997, to identify those scans with the appearance of arterial infarction. Brain scans were routinely carried out on admission to our unit with few exceptions. All ventilated infants were scanned within 24 hours, and most within hours of admission. Subsequent scans were done up to three times in the first week on clinical indication, and thereafter weekly in the neonatal period. The scans were carried out by one of four neonatologists responsible for clinical surveillance, and all the images were reviewed by one of us (PG). The number of planes in which images were printed was not fixed, but adapted to the lesion seen in real time. The scanning machine used was an ATL Ultramark 4 with a mechanical sector scanhead providing 5, 7.5, and $10 \mathrm{MHz}$ frequencies. Almost all the images were scanned using the $7.5 \mathrm{MHz}$ transducer. The results of the scans were confirmed by computed tomography or magnetic resonance imaging in nearly all cases.

Focal brain infarction may present in the early neonatal period as a triangular defect or lacuna filled with cerebrospinal fluid. Pathologists describe ventricular dilatation, shrivelled gyri (ulegyria), and cavities with glial membranes traversing the space left by absent tissue. If such a defect is found in the first two weeks of life prepartum onset is likely. 
After peripartum or early neonatal insults the lesion presents in the neonatal period as a hyperechoic area confined to arterial anatomical boundaries. To be classified as peripartum or neonatal arterial infarction, the hyperechoic lesion had to be confined to the artery ${ }^{1}$; in the case of a known recent event, the focus could not show signs of cystic change within the first 14 days of life; the lesion had to be unilateral, so as not to be confused with watershed infarction types like parasagittal cerebral injury and periventricular leucomalacia; haemorrhage had to be excluded, so parenchymal hyperechogenicity in association with ipsilateral germinal matrix haemorrhage was excluded; larger lesions had to have at least one linear margin. Analagous with adult stroke we did include smaller hyperechoic foci of ellipsoid shape in deep grey matter.

We defined the lesion as a cortical infarct when a pial area of the vessel involved was part of the infarct, even if deep structures were also affected. In contrast, we classified those involving deep grey nuclei or deep white matter without cortical involvement as deep infarcts. To be defined as complete anterior truncal middle cerebral artery infarction, the hyperechoic focus had to be a triangle, with its point at the insula and its base spread across the parasagittal sector from frontal bone to around the central sulcus. The anterior insular gyri were also involved.

To be classified as complete posterior truncal middle cerebral artery infarction, the hyperechoic focus had to point towards the posterior insula on parasagittal section, and have a triangular extension with fuzzy base against the occiput. Viewed through the coronal plane, a blurred hyperechoic area was seen behind and underneath the circular groove of the insula. Parts of the long insular gyri were injured in some.

Clinical and ultrasonographic findings excluded primary haemorrhage, selective neuronal necrosis, venous infarction, tumour, abscess formation and phakomatosis. In some cases distinction from infarction within the area drained by a single small deep vein could not be made. These lesions were not excluded. Hyperpulsatility in the penumbra ${ }^{13}$ and high flow velocity in the (recanalised) artery pointing to the infarct were not considered mandatory. Early fetal arterial infarcts leading to schizencephaly, hydraencephaly, or Moebius' syndrome were excluded.

OUTCOMES

The contralateral motor hemisyndrome was considered severe if the affected lower limb had no useful function (hemiplegia); moderate if some function was preserved; and mild if there was clumsiness with preservation of normal function. Manual function was assessed as follows: severe hemisyndrome: non-functioning hand ${ }^{14}$; moderate: preservation of residual hand function; mild: independent finger movement. Follow up information was not available for all the children. The results of the Mental Developmental Index (MDI) determined by Bayley Scales of Infant Development were available for some children.
Table 1 Association between distribution of infarction and clinical factors

\begin{tabular}{lcc}
\hline & Deep $(n=16)$ & Cortical $(n=24)$ \\
\hline$<37$ weeks gestation & $13(81.3)$ & $5(21.08)$ \\
Neonatal seizures & $2(12.5)$ & $16(66.7)$ \\
Neonatal death & $4(25.0)$ & $1(4.0)$ \\
\hline
\end{tabular}

\section{Results}

From 1988 to 199740 cases of arterial brain infarction were identified (19 boys, 21 girls) involving one of the three major cerebral arteries. In 28 infants the site and characteristics of the lesion were confirmed by computed tomography, or magnetic resonance imaging. The distribution of lesions was as follows: anterior cerebral $(\mathrm{n}=4)$; middle cerebral $(n=26)$; posterior cerebral $(n=10)$. The prevalence of brain infarction between 1993 and 1997 was 12 per 1000 neonates admitted to the neonatal unit. Given that our referral population is about 15000 births a year, the incidence is probably about 0.35 per 1000 total births.

Eighteen of the 40 infants $(45 \%)$ had been born at $<37$ weeks' gestation. The relation between the distribution of lesions, gestational age, and the occurrence of seizures is shown in table 1. Infants with cortical lesions were more likely to be term, to present with neonatal seizures, and to survive.

Putative causes of arterial infarction are summarised in table 2 . There was no association between the vessel type and putative causal factors. The most common association ( $28 \%$ of cases) was pulmonary hypertension or shock, necessitating assisted ventilation. In $25 \%$ of cases there was no obvious "cause" for the infarction.

MIDDLE CEREBRAL ARTERY CORTICAL LESIONS Cortical lesions predominated in infarctions involving the middle cerebral artery. Among the 19 patients with cortical infarction involving the middle cerebral artery 13 patients had lesions confined to the anterior $(n=6)$ or posterior trunk $(n=7)$. The other six patients had complete lesions in the distribution of the main artery $(n=5)$ or very peripheral lesions involving only a small subpart of a trunk $(n=1)$. Details of the 13 patients are shown in table 3. Six out of the seven patients with infarction in the posterior trunk had left sided lesions, in contrast to only one of the six patients with anterior trunk lesions. The gestational ages and incidence of seizures were similar in anterior and posterior truncal lesions. Typical images of the posterior truncal lesion are shown in fig 1 , and of the anterior truncal variant in fig 2 .

Table 2 Putative causes of infarction in territories of major cerebral arteries

\begin{tabular}{lc}
\hline & No (\%) \\
\hline Pulmonary hypertension or shock requiring & \\
$\quad$ assisted ventilation & $11(28)$ \\
Unknown cause & $10(25)$ \\
Septicaemia & $5(13)$ \\
Fetal anaemia & $4(10)$ \\
IUGR and fetal distress & $4(10)$ \\
Factor V Leiden deficiency & $3(8)$ \\
Birth trauma & $2(5)$ \\
Severe intrauterine asphyxia & $1(3)$ \\
\hline
\end{tabular}


Table 3 Trunkal middle cerebral artery infarction

\begin{tabular}{|c|c|c|c|c|}
\hline Case No & Gestational age & Clinical details & Site & Outcome \\
\hline \multicolumn{5}{|c|}{ Entire posterior trunk of the middle cerebral artery } \\
\hline 1 & 36 & $\begin{array}{l}\text { PROM for } 3 \text { days, congenital pneumonia due to early onset group B streptococcal } \\
\text { infection, shock }\end{array}$ & Left & Mild hemisyndrome \\
\hline 2 & 39 & $\begin{array}{l}\text { Vacuum extraction, cephalhaematoma, focal seizures on day } 1 \text {, early onset enterobacter } \\
\text { septicaemia, no shock }\end{array}$ & Left & No sequelae \\
\hline 3 & 38 & $\begin{array}{l}\text { Second twin, cord prolapse, difficult vacuum delivery, subgaleal bleeding, basal subdural } \\
\text { haematoma, focal EEG changes }\end{array}$ & Left & Mild hemisyndrome \\
\hline 4 & 40 & $\begin{array}{l}\text { PROM for } 3 \text { days, vacuum delivery, Apgar scores } 4 / 6 \text {, general seizures on day } 1 \text {, day } 1 \\
\text { Hb } 10.2 \mathrm{~g} / \mathrm{dl} \text {, metabolic acidosis }\end{array}$ & Left & $\begin{array}{l}\text { Mild hemisyndrome, speech } \\
\text { difficulties }\end{array}$ \\
\hline 5 (fig 1) & 37 & Twin, left renal vein thrombosis and adrenal haemorrhage, apc resistance & Right & No sequelae \\
\hline 6 & 38 & Breech delivery, focal seizures on day 2 & Left & $\begin{array}{l}\text { One epileptic insult at } 3 \\
\text { months, no hemisyndrome }\end{array}$ \\
\hline 7 & 33 & $\begin{array}{l}\text { Caesarean section for fetal distress superimposed on growth retardation; no IRDS; APC } \\
\text { resistance; early cystic stage of the haemorrhagic infarction on day } 1\end{array}$ & Left & No follow up \\
\hline \multicolumn{5}{|c|}{ Entire anterior trunk of the middle cerebral artery } \\
\hline 8 (fig 2) & 34 & $\begin{array}{l}\text { IUGR, lost beat to beat variation, brief postnatal acidosis (the area involved span the } \\
\text { right frontal and part of the parietal lobe's convexity, including rolandic cortex) }\end{array}$ & Right & Severe hemiplegia, MDI 84 \\
\hline 9 & 40 & $\begin{array}{l}\text { Focal seizures on day } 2, \mathrm{APC} \text { resistance in propositus and asymptomatic father } \\
\text { (presentation was with a right frontal lobe haematoma; the evolution showed this to } \\
\text { be infarction with late neonatal regression with multiple cysts) }\end{array}$ & Right & $\begin{array}{l}\text { Normal at } 12 \text { months, right } \\
\text { predominance }\end{array}$ \\
\hline \multicolumn{5}{|c|}{ Within part of the anterior trunk of the middle cerebral artery } \\
\hline 10 & 30 & $\begin{array}{l}\text { Death of co-twin at } 26 \text { weeks, IRDS (the affected vessel was probably a branch of the } \\
\text { prefrontal artery) }\end{array}$ & Right & Unknown \\
\hline 11 & 38 & Second day seizures in a healthy infant & Left & Unknown \\
\hline 12 & 38 & $\begin{array}{l}\text { Coarctation aorta, oesophageal atresia; systemic acidosis (haemorrhagic leucomalacia } \\
\text { and right anterior middle cerebral artery infarction were associated in this child) }\end{array}$ & Right & Unknown \\
\hline 13 & 40 & $\begin{array}{l}\text { Oligohydramnios and stunted fetal growth for } 2 \text { weeks, chronic fetomaternal transfusion } \\
\text { (Kleihauer-Betke } 6 \% \text { ), focal seizures on day } 2 \text { (the area involved may have been } \\
\text { within the prefrontal and precentral branches of the middle cerebral artery or may } \\
\text { have been a watershed zone with the anterior cerebral artery) }\end{array}$ & Right & Normal at 12 months \\
\hline
\end{tabular}

Key: PROM = Premature rupture of membrane; IRDS = Idiopathic respiratory distress syndrome; APC = Activated protein C resistance (factor V Leiden).

The outcome was known in 11 of the 13 infants with truncal middle cerebral artery lesions involving the cortex. Only one patient was hemiplegic and this was associated with an anterior truncal lesion involving the rolandic cortex. Three patients with posterior truncal lesions had a mild hemisyndrome. Most of the patients therefore did not have hemiplegia, a phenomenon previously reported as a sequel to infarction in the complete middle cerebral artery.

\section{Discussion}

The estimated incidence of all types of focal cerebral infarction in our study $(0.35$ per 1000 total births) was 3-4 times higher than the results of studies in term infants who were diagnosed in later childhood. ${ }^{15}$ This was partly due to the inclusion in our study of infants with

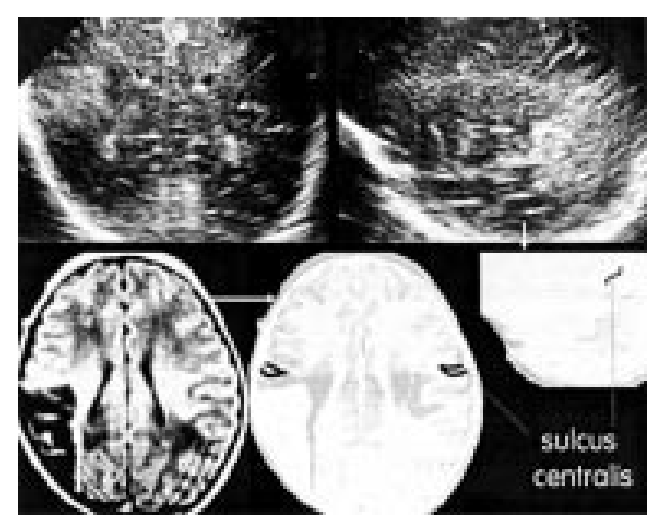

Figure 1 Sonograms $(7.5 \mathrm{MHz})$ through the coronal (top) and parasagittal planes of the right hemisphere and $T 1$ weighted axial magnetic resonance image in the late neonatal period in case 5. The position of the central groove is shown in relation to the infarct in the posterior section of the middle cerebral artery. The infarct is pial as the striatum is not affected. isolated deep infarctions. Aside from perinatal asphyxia, stroke is the most common cause of neonatal seizures at term. ${ }^{16}{ }^{17}$ As anticipated, we observed that seizures were more frequently related to cortical than to deep infarcts. Like many others before us, we could not find a cause for neonatal stroke in a high proportion of cases. ${ }^{318-21}$ In our experience perinatal asphyxia is a rare cause of stroke. However, we confirmed an association between stroke and pulmonary hypertension. ${ }^{22}$

Hemiplegia may follow infarction in areas of the brain supplied by the entire middle cerebral artery, in the complete set of cortical branches of the middle cerebral artery, in the anterior or posterior trunk of the middle cerebral artery, in

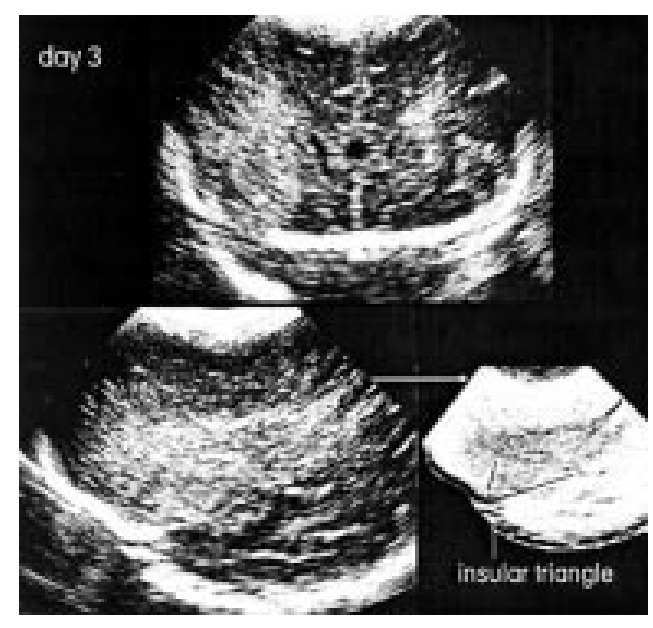

Figure 2 Sonograms $(7.5 \mathrm{MHz})$ on day 3 showing coronal (top) and parasagittal planes (bottom) of case 8 . Infarction is evident within the anterior trunk of the middle cerebral artery. Parasagittal plane shows involvement of the central groove which explains the subsequent hemiplegia; necrosis within the entire anterior trunk involves not only the central area but also the insular triangle. 


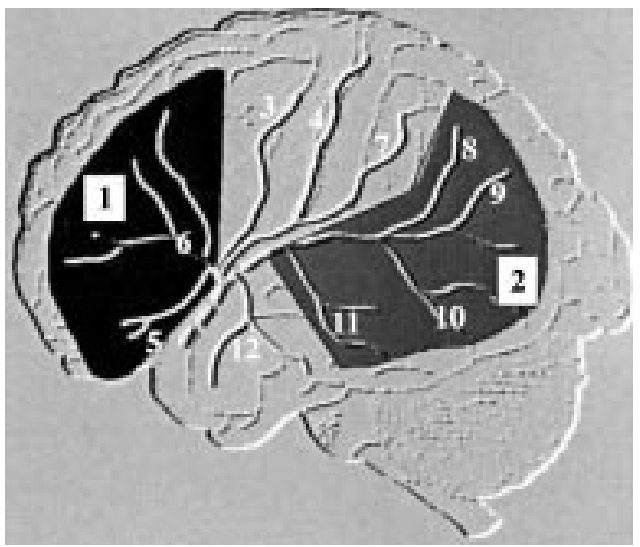

Figure 3 View of the left cerebral convexity showing the main branches of the middle cerebral artery: 1 anterior trunk; 2 posterior trunk; 3 precentral artery; 4 central artery; 5 lateral orbitofrontal artery; 6 prefrontal artery; 7 anterior parietal artery; 8 posterior parietal artery; 9 angular artery; 10 posterior temporal artery; 11 anterior temporal artery; 12 temporo-polar artery.

the lenticulo-striate branches of the middle cerebral artery or in the anterior choroidal artery. The main purpose of this study was to draw attention to the occurrence of cortical infarction in areas of the cortex supplied by the anterior and posterior trunks of the middle cerebral artery. The precise anatomy of the branches of the middle cerebral artery varies, but the usual arrangement is the common stem dividing at the insula into anterior and posterior trunks (fig 3).

The anterior trunk splits into prefrontal, precentral, central and anterior parietal arteries. It is not uncommon for the central and anterior parietal artery to split off from the main artery and not the anterior trunk. These vessels irrigate the cortex on the cerebral convexity up to the level of the postcentral gyrus. Infarction of a complete anterior trunk would involve the primary motor cortex (case 8), whereas partial infarction limited to the premotor and/or supplementary motor area could lead to subtle contralateral disturbances in motor coordination without hemiplegia (cases 9 and 10). We speculate that frontal haematoma at term may be the haemorrhagic version of infarction within the anterior trunk of the middle cerebral artery (case 9). In this patient the area involved did not become cystic until the third week of life. Subsequent disappearance of the lesion after an intermediate stage of multiple small cysts is unlike the usual regression mode of pure haemorrhage. We observed anterior truncal stroke and leucomalacia (watershed infarction of white matter) in the same child (case 12). Unlike periventricular leucomalacia and anterior cerebral artery infarction, hemiplegia following middle cerebral artery cortical stroke predominantly affects the upper limb and leads to marked astereognosis. ${ }^{23}$ Similar cases of anterior truncal stroke have been described with computed tomography and magnetic resonance imaging. ${ }^{24-27}$

The posterior trunk of the middle cerebral artery perfuses the temporal and occipital lobe convexities and a variable portion of the poste- rior parietal lobe. Its terminal branch, the angular artery, runs along the horizontal lower border of the insula behind the postcentral gyrus. Although anatomic variability may cause the posterior trunk to extend as far as the motor cortex, this is uncommon. The central groove can be localised with ultrasonography (figs 1 and 2).

Infarction within the posterior trunk affects the convex posterior temporal, parietal, and occipital lobe. Video recording of sonograms may permit retrospective examination of involvement of the rolandic area. The sonograms were strikingly similar in all patients with this type of infarction, and comparable cases have been reported, for it to be considered a separate entity. ${ }^{2425} 28{ }^{29}$ In spite of a reported normal outcome, ${ }^{242528} 29$ we recorded contralateral motor and orientation disturbances in half our infants with infarction in the posterior trunk. Case 3 was compared with her healthy male co-twin at 3 years of age by her mother: the account is typical: "She still cannot turn off a tap, invariably turning it the wrong way; she was much older before she mastered her tricycle because she pedalled backward; she cannot recognise the face in a photo when it was cut into pieces; inside the toilet, once the door is closed, she found it difficult to differentiate the door from the walls, whereas her brother easily remembers where the door was."

The substrate for linguistic specialisation is present at birth, so that left and not right hemispheric lesions may cause permanent symptoms. Residual epilepsy seems to be rare. Smaller neonatal infarctions in the posterior trunk may well go undetected. For example, one infant without a hemisyndrome (case 2) had a normal follow up computed tomogram, suggesting that the neonatal hyperechoic focus (and attenuated corresponding computed tomographic area) had been ischaemic rather than necrotic and had completely resolved.

Caution is needed when assessing the probable perinatal cause of hemiplegia from brain imaging in childhood. ${ }^{3031}$ One confounder is the existence of trans-synaptic antero- and retrograde neuronal atrophy. Cortical infarction over an extensive frontoparietal area perfused by the middle cerebral artery will cause delayed thalamic atrophy ${ }^{30}$ and macroscopic ipsilateral atrophy of the corticospinal tract at brainstem level above the decussation. ${ }^{27}{ }^{32}$ Precise delineation of the original focus of damage may not be straightforward when reviewed subsequently.

As fewer than half the survivors with infarction of truncal distribution developed severe hemiplegia it is clear that the incidence of focal infarction in the perinatal period will be underestimated by basing estimates on observations in children with hemiplegia. Infarction involving the complete middle cerebral artery leads to contralateral hemiplegia, with the arm being more affected than the leg, and with astereognosis. ${ }^{818} 20213334$ Cognitive dysfunction tends to coincide with residual epilepsy. Details are available of perceptual performance and communication problems ${ }^{34}$ and language 
difficulties. ${ }^{6}$ The risk of residual epilepsy is between 25 and $50 \% .^{581535}$

It would be impossible to deduce the number of lesions we missed by using ultrasonography as a screening tool. On the other hand, there is no other technique available for screening large numbers of sick infants. As clinical markers for arterial infarction are insensitive, except, perhaps, for seizures, limb pallor, and apnoea in term neonates, sonographic surveillance assumes greater importance. ${ }^{36}$ The chance of finding a cerebral infarct is $30 \%$ in term newborn infants with seizures, and a five minute Apgar score of at least seven is likely. ${ }^{16}$ The limits of ultrasonography are in the description of posterior cerebral artery infarction and infarction between the fontanelles. Similarly, it is unlikely that ultrasonography will be helpful in brainstem or cerebellar arterial infarction.

More widespread sonographic detection might facilitate collaborative studies of the treatment of neonatal stroke. So far, attempts at treatment have been erratic. ${ }^{21}{ }^{37}$ Infarction is likely if systemic hypoperfusion is associated with variable anatomy of the cerebral arteries. The study of the normal arterial anatomy of the newborn brain with Doppler or spectral analysis may be useful in this respect. Another major advance would be illustration of the vessel itself without invasive angiography. Magnetic resonance angiography looks promising in this regard, at least for vessels of more than $1 \mathrm{~mm}$ in width. ${ }^{37-39}$ Additional early information may be gathered with colour Doppler sonography, ${ }^{40}$ power Doppler sonography, ${ }^{41}$ and magnetic resonance spectroscopy. ${ }^{42}$

1 Bogousslavsky J, Caplan L. Stroke syndromes. Cambridge: CUP, 1995

2 Govaert P. Cranial haemorrhage in the term newborn infant. In: Clinics in Developmental Medicine. 129. London: McKeith Press, 1993:118-126.

3 Volpe JJ. Neurology of the newborn. Philadelphia: WB Saunders Company, 1995: 303-7.

4 Trauner DA, Mannino FL. Neurodevelopmental outcome after neonatal cerebrovascular incident. 7 Pediat 1986;108:459-61.

5 Sran SK, Baumann RJ. Outcome of neonatal strokes. Am F Dis Child 1988;142:1086-8.

6 Wulfeck BB, Trauner DA, Tallal PA. Neurologic, cognitive, and linguistic features of infants after early stroke. Pediatr Neurol 1991;7:266-9.

7 Trauner DA, Chase C, Walker P, Wulfeck B. Neurologic profiles of infants and children after perinatal stroke. Pediprofiles of infants and childr.
atr Neurol 1993;9:383-6.

8 Koelfen W, Freund M, Varnholt V. Neonatal stroke involving the middle cerebral artery in term infants: clinical presentation, EEG and imaging studies, and outcome. Dev Med Child Neurol 1995; 37:204-12.

9 de Vries LS, Regev R, Connell JA, Bydder GM, Dubowitz LMS. Localized cerebral infarction in the premature infant: an ultrasound diagnosis correlated with computed tomography and magnetic resonance imaging. Pediatrics 1988;81:36-40.

10 de Vries LS, Smet M, Goemans N, Wilms G, Devlieger H, Casaer P. Unilateral thalamic haemorrhage in the preterm and fullterm newborn. Neuropediatrics 1992;23:153-6.

11 de Vries LS, Groenendaal F, Eken P, van Haastert IC, Rademaker KJ, Meiners LC. Infarcts in the vascular distribution of the middle cerebral artery in preterm and fullterm infants. Neuropediatrics 1997;28:88-96.

fullterm infants. Neuropediatrics 1997;28:88-96.
12 Maegaki Y, Maeoka Y, Ishii S, et al. Mechanisms of central motor reorganization in pediatric hemiplegic patients. Neuropediatrics 1997;28:168-74.
13 Hill A, Martin DJ, Daneman A, Fitz CR. Focal ischemic cerebral injury in the newborn: diagnosis by ultrasound scan and correlation with computed tomographic scan. Pcan and correlation with

14 Claeys V, Deonna T, Chrzanowski R. Congenital hemiparesis: the spectrum of lesions, a clinical and computerize tomography study. Helv Paediatr Acta 1983;38:439-55.

15 Uvebrant P. Hemiplegic cerebral palsy:aetiology and outcome. Acta Paediatrica Scandinavica 1988; Supp1 345.

6 Lien JM, Towers CV, Quilligan EJ, de Veciana M, Toohey JS, Morgan MA. Term early-onset neonatal seizures obstetric characteristics, etiologic classifications, and perinatal care. Obstet Gynecol 1995;85:163-9.

17 Estan J, Hope P. Unilateral neonatal cerebral infarction in full term infants. Arch Dis Child Fetal Neonatal Ed 1997;76: F88-F93.

18 Mantovani J-F, Gerber JF. Idiopathic neonatal cerebral infarction. Am f Dis Child 1984;138: 359-62.

19 Levy SR, Abroms I-F, Marshall PC, Rosquete EE. Seizures and cerebral infarction in the full-term newborn. Ann Neurol 1985;17:366-70

20 Roodhooft A-M, Parizel PM, Van Acker KJ, Deprettere AJR, Van Reempts PJ. Idiopathic cerebral arterial infarction with paucity of symptoms in the full-term neonate. Pediatrics 1987;80: 381-5.

21 Raine J, Davies H, Gamsu HR. Multiple idiopathic emboli in a full term neonate. Acta Paediatr Scand 1989;78:644-6.

2 Klesh KW, Murphy TF, Scher MS, Buchanan DE, Maxwell $\mathrm{EP}$, Guthrie RD. Cerebral infarction in persistent pulmonary hypertension of the newborn. Am $\mathcal{f}$ Dis Child 1987;141:852-7.

23 Molteni B, Oleari G, Fedrizzi E, Bracchi M. Relation between CT patterns, clinical findings and etiological factors in children born at term, affected by congenital hemiparesis. Neuropediatrics 1987; 18:75-80.

24 Billard C, Dulac O, Diebler C. Ramollissement cérébral ischémique du nouveau-né. Arch Franç Pédiatr 1982;39:677-83.

25 Clancy R, Malin S, Larague D, Baumgart S, Younkin D. Focal motor seizures heralding stroke in full-term neonates. Am f Dis Child 1985;139:601-6.

26 Baumann RJ, Carr WA, Shuman RM. Patterns of cerebral arterial injury in children with neurological disabilities. $\mathcal{f}$ Child Neurol 1987;2:298-306.

27 Bouza H, Dubowitz LMS, Rutherford M, Pennock JM. Prediction of outcome in children with congenital hemiplegia: a magnetic resonance imaging study. Neuropediatrics 1994;25:60-6.

28 Mannino FL, Trauner DA. Stroke in neonates. $\mathcal{F}$ Pediatr 1983;102:605-10.

29 Fujimoto S, Yokochi K, Togari H, et al. Neonatal cerebral infarction: symptoms, CT findings and prognosis. Brain Devel 1992;14:48-52.

30 Giroud N, Fayolle H, Martin D, et al. Late thalamic atrophy in infarction of the middle cerebral artery territory in neonates. Child Nerv Syst 1995;11:133-6.

31 Allan WC, Riviello JJ. Perinatal cerebrovascular disease in the neonate. Pediatr Clin North Am 1992; 39:621-50.

32 SmithCD, Baumann RJ. Clinical features and magnetic resonance imaging in congenital and childhood stroke. $\mathcal{F}$ Child Neurol 1991;6:263-72.

33 Gudinchet F, Dreyer J-L, Payot M, Duvoisin B, Laurin R. Imaging of neonatal arterial thrombosis. Arch Dis Child 1991;66:1158-9.

34 Koelfen W, Freund M, König S, Varnholt V, Rohr H, Schultze C. Results of parenchymal and angiographic magnetic resonance imaging and neuropsychological testing of children after stroke as neonates. Eur $\mathcal{F}$ Pediatr 1993;152:1030-5.

35 Kotlarek F, Rodewig R, Brüll D. Computed tomographic findings in congenital hemiparesis in childhood and their relation to etiology and prognosis. Neuropediatrics 1981;12:101-9.

36 Perlman JM, Rollins NK, Evans D. Neonatal stroke : clinical characteristics and cerebral blood flow velocity measurements. Pediatr Neurol 1994;11:281-4.

37 Gould RJ, Black K, Pavlakis SG. Neonatal cerebral arterial thrombosis: protein C deficiency. $\mathcal{F}$ Child Neurol 1996;11:250-2

38 Koelfen W, Wentz U, Freund M, Schultze C. Magnetic resonance angiography in 140 neuropediatric patients. Pediatr Neurol 1995;12:31-8.

39 Guajardo L, Strauss A, Amster J. Idiopathic cerebral infarction and upper limb ischemia in neonates. Am f Perinatol 1994;11:119-22.

40 Taylor GA. Alterations in regional cerebtral blood flow in neonatal stroke : preliminary findings with color Doppler sonography. Pediatr Radiol 1994;24:111-15.

41 Steventon DM, John PR. Power Doppler ultrasound appearances of neonatal ischaemic brain injury. Pediatr Radiol 1997;27:147-9.

42 Groenendaal F, van der Grond J, Witkamp TD, De Vries LS. Magnetic resonance spectroscopic imaging in neonatal stroke. Neuropediatrics 1995;26:243-8. 